\title{
Tailings beach slopes as a dimensionless parameter of non-Newtonian flows
}

\author{
T Errázuriz Golder Associates S.A., Chile
}

\begin{abstract}
The application of highly thickened tailings technologies is rapidly increasing due to the perceived benefits with respect to reduction of environmental impacts, water saving and potential reductions in dam size and impoundment footprint. Evaluation of these potential benefits requires that during design stages an understanding is developed of the range of feasible beach slopes to be achieved during deposition. A comprehensive evaluation of the operational factors influencing the beach formation process is paramount to ensure that expected performance during design stages is met throughout operations.

This paper presents the derivation of a dimensionless parameter for non-Newtonian flows, associated with sheet flows on an inclined plane, which directly relates to the tailings beach slope expected to be formed due to subaerial disposal. This dimensionless parameter provides a closed expression for estimating tailings beach slopes based on rheological properties and discharge rates considering that sheet flow mechanisms occur. Conditions for sheet flow occurrence, such as level of further dewatering of the beach after deposition, active discharge times and geometry of active discharge areas, can be derived within this formulation.

The dimensionless parameter and conditions found to promote sheet flow also allow to address the advantages and limitations of different discharge operation strategies, such as operating the tailings facility by sectors (allowing drying cycles) of varying geometries.

Evaluation of this approach in the light of case histories is presented. Finally, discussion on how to evaluate the potential of having concave tailings beach profiles within this formulation is provided.
\end{abstract}

Keywords: tailings beach slope estimation, tailings surface disposal, thickened tailings deposits design

\section{Introduction}

This article presents the derivation of a tailings beach slope model based on a dimensionless formulation. The model is derived for flow properties associated with non-Newtonian sheet flows along tailings beaches and take into account key parameters that dictate flow behaviour such as the Reynolds number and fluid rheology.

Design and operational measures for promoting sheet flow and the benefits are explored with this model, as well as global stack stability considerations. The model is also validated using field data.

\section{Applicability of the model}

Tailings beach formation processes can involve a variety of flow regimes including supercritical or subcritical, turbulent or laminar and channelised or spreading flows (Simms et al. 2011). These conditions influence the overall shape and geometry of the tailings beaches within the impoundment, and therefore should be considered in the process of defining the model to estimate beach slopes for design of tailings storage facilities. Simms et al. (2011) provided a review of different beach slope models, their features and considerations regarding the applicability of each model to the different flow regimes. A key conclusion is that the applicability of the models is dependent on the flow regime being evaluated.

This paper focuses on a model suitable for assessing sheet flow regimes of non-Newtonian fluids which allow for the formation process of steeper beach slopes compared to other flow regimes. Key mechanisms resulting in steeper beach slopes are associated with the reductions of the hydraulic radius (i.e. larger wetted 
perimeter) and associated increase of energy losses through friction. In addition, the drying and desiccation processes of thickened tailings and their ability to form a surface boundary condition that induces the formation of a 'flow plane' with a lower erodibility potential are required in the context of promoting sheet flows (Figure 1).

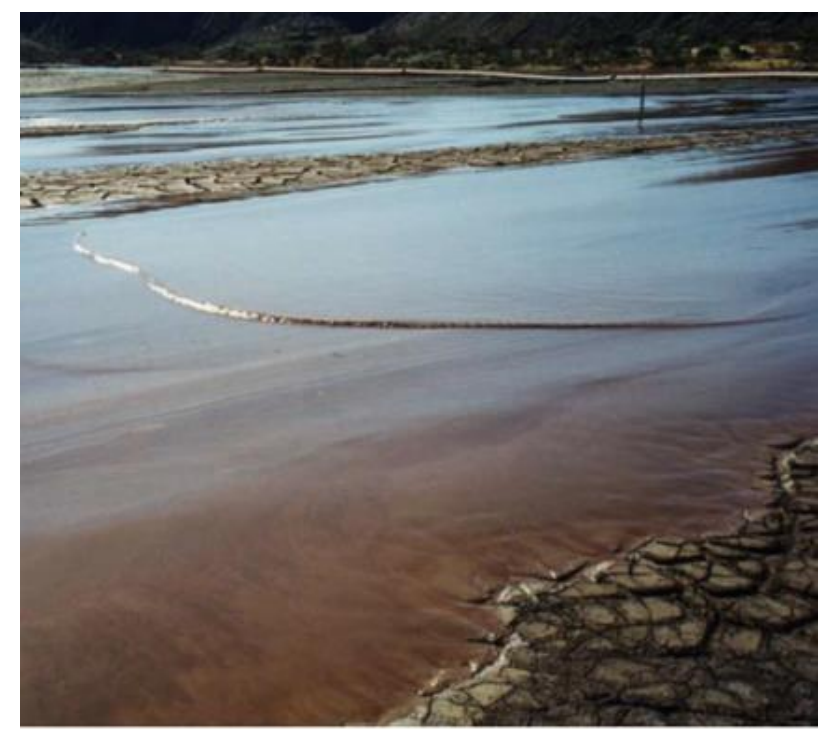

Figure 1 Sheet flow example on tailings beaches on top of dried tailings (extracted from Jewell 2010)

\section{$3 \quad$ Model formulation}

The model formulation is based on the Navier-Stokes equations adjusted to represent sheet flow of non-Newtonian fluids over an inclined plane as per Ihle and Tamburrino (2009). The model parameters are analysed to explore solutions that are representative of tailings sheet flows building up tailings beaches.

\subsection{Equations for non-Newtonian sheet flows on an inclined plane}

The beach slope estimation model presented herein has been formulated based on the set of equations describing the movement of viscoplastic sheet flows over an inclined plane developed by Ihle and Tamburrino (2009). This model defined two dimensionless parameters ( $h$ and $N$ ) for the assessment of steady-state flow solutions of the Navier-Stokes equations that apply to two-dimensional homogenous thin Bingham plastic flow with constant discharge rate on a gentle inclined plane (Figure 2).

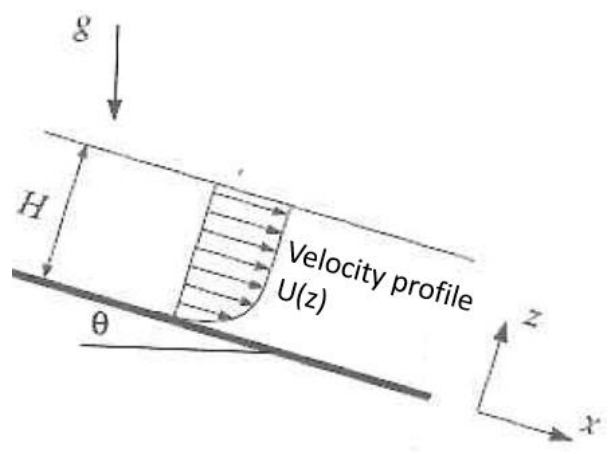

Figure 2 Schematic representation of the two-dimensional thin viscoplastic flow on an inclined plane considered for the model (modified from Ihle \& Tamburrino 2009) 
These two dimensionless parameters are defined by Equations 1 and 2 (Ihle \& Tamburrino 2009).

$$
\begin{gathered}
h=\frac{H \gamma \sin \theta}{\tau_{y}} \\
N=\frac{6 \eta q(\gamma \sin \theta)^{2}}{\tau_{y}{ }^{3}}
\end{gathered}
$$

where:

$H$ and $\gamma=$ height of the sheet flow and unit weight of the tailings pulp.

$\tau_{y}$ and $\eta=$ yield stress and plastic viscosity (Bingham plastic model).

$q$ and $\theta=$ discharge rate per unit width and angle of the inclined plane (bed of sheet flow).

These parameters are related through Equation 3 (Ihle \& Tamburrino 2009) as follows:

$$
N-(h-1)^{2}(2 h+1)=0
$$

Equation 3 has a real solution only if $N(N-1)>0$ (Ihle \& Tamburrino 2009). The solution of Equation 3 is given by Equation 4 (Ihle \& Tamburrino 2009).

$$
h=\frac{1}{2^{\frac{2}{3}}}\left\{\left[N+N^{\frac{1}{2}}(N-1)^{\frac{1}{2}}-\frac{1}{2}\right]^{\frac{1}{3}}+\left[N-N^{\frac{1}{2}}(N-1)^{\frac{1}{2}}-\frac{1}{2}\right]^{\frac{1}{3}}+\frac{1}{2^{\frac{1}{3}}}\right\}
$$

Ihle and Tamburrino (2009) noted that the dimensionless parameter $\mathrm{N}$ functions as a control parameter of the flow and $\mathrm{h}$ represents a dimensionless length scale of the sheet flow, where $\mathrm{h}$ monotonically increases with $\mathrm{N}$.

Through this analysis, they derived that the height $\mathrm{H}$ and the average velocity of the sheet flow $\mathrm{U}$ could be defined based on the discharge rate, Bingham plastic model parameters, pulp unit weight, slope of the inclined plane, and a control parameter $\mathrm{N}$, which defines the flow regime, through the following expression:

$$
\begin{aligned}
& H=\frac{h \tau_{y}}{\gamma \sin \theta} \\
& U=\frac{q \gamma \sin \theta}{h \tau_{y}}
\end{aligned}
$$

This formulation can be used for evaluating different flow conditions parameterised by $\mathrm{N}$.

\subsection{Derivation of the beach slope as a dimensionless parameter of a non-Newtonian sheet flow}

The model formulation presented herein involves the interpretation of the control parameter $\mathrm{N}$, in the context of an evaluation of tailings beach slopes.

\subsubsection{Definition of a limit condition criteria for beach slopes and associated dimensionless parameter $N$}

The movement of non-Newtonian flows on an inclined plane has shown to be governed by the control parameter $\mathrm{N}$, which is defined by relevant fluid mechanics properties and the angle of the inclined plane (a given variable in Ihle and Tamburrino (2009) formulation). A key difference in the process of defining beach slopes for tailings facilities (built through deposition of multiple inclined layers) is that the bed angle (formed beach slopes) is an unknown variable. In fact, bed angle or beach slopes is the sought after variable needed for the purpose of engineering designs. As such, this model formulation has been developed assuming that the bed angle value is unknown.

Considering that through tailings deposition, the tailings flow will generate its own bed, the model has been constructed based on the existence of a limiting condition criteria that describes the equilibrium state of such auto-generated system. Upon evaluation of the construction of parameter $\mathrm{N}$ and the associated restriction 
of having real solutions only if $N(N-1)>0$, it is possible to think that this is achieved when $N=1$. The approach of a limiting condition for beach slope estimation purposes has been recognised by different authors, such as McPhail $(1995,2008)$ using entropy maximisation criteria, Fitton (2007) and Pirouz and Williams (2007) using critical settling velocity criteria, or Li (2011) and Fourie and Gawu (2010) using limit equilibrium criteria.

For a given discharge rate and fluid properties, $\mathrm{N}$ becomes lower when the inclined plane angle $(\theta)$ is reduced. The minimum bed angle that still ensures a real root solution of the steady-state condition is obtained when $\mathrm{N}=1$. This can be interpreted as the minimum bed angle needed to make gravity forces balanced with viscous forces and maintain steady-state movement of the fluid. The critical condition between the case of a tailings flow that can travel in a steady-state condition along the beach and that of flow that traverses a certain distance prior to stopping due to energy loss is considered here as a critical condition for the beach formation process.

From Equation 2, defining $\mathrm{N}=1$ and considering $\sin \theta \approx \theta$ in the context of gentle slopes, it is possible to derive a dimensionless parameter representing the tailings beach slope.

$$
\theta_{\text {beach }}=\frac{\tau_{y^{\frac{3}{2}}}}{\gamma \sqrt{6 q \eta}}
$$

This dimensionless parameter $\theta_{\text {beach }}$ represents the ratio between the forces that cause the non-Newtonian fluid to remain stagnant and the forces that cause the non-Newtonian fluid to initiate flow.

As observed from Equation 7, the only variable that should contribute to keep the fluid stagnant is the yield stress that in fact appears alone in the numerator of $\theta_{\text {beach }}$.

Accordingly, the denominator of $\theta_{\text {beach }}$ contains the variables promoting the initiation of flow by means of increasing the gravity-driving forces (i.e. increasing the shear stress at the fluid base). One of these variables is the pulp unit weight due to increases in the fluid mass. The others are the discharge rate coupled with the plastic viscosity due to increases in the flow height. For the same fluid viscosity (i.e. the same flow velocity), an increment of the discharge rate leads to an increment of the flow height to meet the mass conservation of the flow. Likewise, for the same discharge rate, an increment of the viscosity (i.e. a reduction of the flow velocity) leads to an increment of the flow height.

This interpretation is consistent with the conceptual meaning of the yield stress and the plastic viscosity for a non-Newtonian fluid where 'the yield stress represents the difficulty of a fluid for initiate flow, while the viscosity represents the difficulty of the fluid to flow quickly'.

\subsubsection{Beach slope dimensionless parameter applied to field conditions}

The sheet flow equations used for deriving $\theta_{\text {beach }}$ are valid for two-dimensional flow conditions, i.e. an infinite width. In the operational context, tailings flows are deposited from a certain number of discharge points (or spigots), and sheet flows progressively extend in width (W) as they are deposited and flow along the impoundment. Considering that the flow height is small with respect to this expanded width, it is possible to rewrite Equation 7 in terms of the total tailings discharge rate (volume in time), the number of spigots operating simultaneously and the width of sheet flow (an unknown variable) developed from each discharge point, as shown in Equation 8.

$$
\theta_{\text {beach }}=\sqrt{\frac{n W \tau_{y}^{3}}{6 Q \eta \gamma^{2}}}
$$

where:
$W \quad=$ width of sheet flow at the beach generated from each spigot.
$n=$ number of spigots discharging simultaneously.
$Q \quad=$ total tailings discharge rate (sum of all spigots' discharge rate). 
Although this expression incorporates a new unknown variable (W), the width of sheet flow is subject to a limiting condition criteria that may be applied for the purposes of deriving a closed solution. This limiting condition is the critical lateral spread of sheet flow under a constant discharge rate.

The fact that Equation 8 meets the limit condition $\mathrm{N}=1$ for any given $\mathrm{W}$, implies that a critical force balance represented by $\theta_{\text {beach }}$ can occur for different levels of laminar regime. As such, depending on the value of $W$, the critical flow will be more or less laminar in terms of the Reynolds number. In this regard, wider flows (larger W) result in lower Reynolds numbers associated to more-laminar flow for the same discharge rate and fluid properties.

From this finding, the limiting condition for sheet flow lateral spreading should be associated with where the flow tends to the minimum transport energy. This results in a tendency for the flow to have the minimum width for increasing the Reynolds number and then decreasing frictional losses (as frictional losses are inversely proportional to the Reynolds number for laminar flows).

When the Reynolds number increases, the laminar flow is more prone to become turbulent. Following a limit criteria rationale similar to Fitton (2007) and Pirouz and Williams (2007), the characteristic condition of tailings flows forming beaches is not compatible with an increased turbulence that can keep all the particles in suspension within the flow.

From the above, the limiting criteria for sheet flows building up tailings beaches has been defined as when the flow tends to the maximum Reynolds number within a laminar regime, i.e. to the transitional Reynolds number between laminar and turbulent regimes.

Ihle and Tamburrino (2009) addressed the transition between laminar and turbulent flow, considering the work by Naik (1983). The Reynolds number $R e$ and the Hedström number $\mathrm{He}$ are defined by Equations 9 and 10, and the critical Reynolds number $R e_{c}$ is given by Equations 11 and 12 (Naik 1983 in Ihle \& Tamburrino 2009).

$$
\begin{gathered}
R e=\frac{4 \gamma U R_{h}}{g \eta}=\frac{4 \gamma U H}{g \eta}=\frac{4 \gamma Q}{g \eta n W} \\
H e=\frac{16 \gamma R_{h}^{2} \tau_{y}}{g \eta^{2}}=\frac{16 \gamma H^{2} \tau_{y}}{g \eta^{2}} \\
R e_{c}=\frac{H e}{a}\left(1-b r_{t}+c r_{t}^{3}\right) \\
\frac{r_{t}}{\left(1-r_{t}\right)^{3}}=\frac{H e}{d}
\end{gathered}
$$

where:

$$
\begin{array}{ll}
R_{h} \text { and } g & =\text { hydraulic radius (for sheet flows tends to } \mathrm{H} \text { ) and gravity acceleration. } \\
r_{t} & =\text { auxiliary variable for Equation } 12, \text { to be included in Equation } 11 . \\
a, b, c \text { and } d & =\quad \text { parameters equal to } 12, \frac{3}{2}, \frac{1}{2} \text { and } 48,000 \text { respectively (Naik 1983). }
\end{array}
$$

From Equation 9, it is possible to have an expression for the width $W$ of tailings sheet flows forming tailings beaches, by replacing $R e$ by $R e_{c}$, which results in Equation 13 .

$$
W=\frac{4 \gamma Q}{n g \eta \operatorname{Re}_{c}}
$$

Replacing Equation 13 in Equation 8, the following is obtained for $\theta_{\text {beach }}$.

$$
\theta_{\text {beach }}=\sqrt{\frac{\tau_{y}{ }^{3}}{\frac{3}{2} g \gamma \eta^{2} R e_{c}}}
$$

Equation 14 allows use of the dimensionless parameter $\theta_{\text {beach }}$ for estimating tailings beach slopes for use in practical applications of tailings deposition, provided that variables $Q, n, \tau_{y}, \eta$ and $\gamma$ are known. In Section 4 , this expression is analysed and validated with field data. Solution of Equation 14 with respect to $\theta_{\text {beach }}$ requires an iterative procedure as it is an implicit equation. 
The solving procedure starts with an arbitrary $\mathrm{W}$ value and calculates $\theta_{\text {beach }}$ using Equation 8 . With this, $\theta_{\text {beach }}$ $\mathrm{H}$ is determined using Equation 5, considering $\theta=\theta_{\text {beach }}$ and $h=\frac{3}{2}(\mathrm{~N}=1$ in Equation 4). With the calculated $\mathrm{H}$, the $\mathrm{He}$ number is calculated with Equation 10 and then the $\operatorname{Re}_{c}$ (Equation 11 and solving the implicit Equation 12 for $r_{t}$ ). Finally, the $R e$ number (Equation 9) has to be compared with the $R e_{c}$, and the $W$ value modified until $R e=R e_{c}$. The value of $\theta_{\text {beach }}$ for sheet flow is obtained when this condition is met.

The $\theta_{\text {beach }}$ expression given by Equation 14 was derived considering a general form, where the number of spigots is included as one of the input variables.

Nevertheless, when different numbers of spigots are evaluated for a given total discharge rate and fluid properties with Equation 14, the beach slope obtained is an invariant, as well as the sum of the flow widths per spigots obtained, using Equation 13.

This implies that for given tailings production rate and fluid properties, the beach slope generated by sheet flows is an inherent property of these conditions, i.e. there is a unique critical Reynolds number $R e_{c}$ for that situation.

Then, for having access to this 'characteristic sheet flow beach slope', non-erodible flow basal surfaces for inhibiting channelised flows as much as possible and sufficient width at the field for developing sheet flows (at least the invariant total width obtained as the sum of all individual flow widths per spigot using Equation 13) are required.

Notwithstanding the above, this formulation shows the practical relevance of having multiple spigots, which is in fact an empirical observation form tailings projects practice. If a small number of spigots are used for the given total discharge rate, the width expansion required for having a sheet flow from each single discharge point may become too drastic, and more prone to generate erosion channels instead of sheet flows. In this sense, using multiple spigots becomes a requisite for having a proper development of sheet flows at the beaches.

A further consequence of having a sheet flow type is that the confluence of individual sheet flows from different discharge points should not be a mechanism for reducing the beach slope. This is because the total width of the sheet flow is an invariant. If many originally individual sheet flows converge, the hydraulic radius (given by the height of the flow) will not vary if there is sufficient space for the development of a new wider sheet flow having its corresponding invariant total width (i.e. the sum of all single sheet flow widths converged). Again, having a non-erodible previous tailings surface at the flow base is the key aspect for that situation. It's worth noting that McPhail (2015) provides a consistent rationale in which the confluence of fluxes are a mechanism for reducing beach slopes in the context of auto-channelised tailings flows at the beaches, in which case the hydraulic radius is in fact subject to be affected by any convergence.

\subsection{Beach profile assessment - a concavity model}

Thickened tailings beaches have shown a tendency for exhibiting concave profiles, and this feature has been discussed by different authors (Fitton 2007; Li 2011; McPhail et al. 2017; Simms et al. 2011). The causes of the concavity can be explained by several factors that are not mutually exclusive (Simms et al. 2011). These factors can be related to an inherent feature of the beach formation process from the point of view of the entropy maximisation (McPhail 2008), tailings variability during the formation period of a tailings beach (Fitton 2007) and rheology changes that tailings flows undergo as they traverse through the impoundment (Li 2011; McPhail et al. 2017).

\subsubsection{Steady-state concave beach profile}

Blight and Bentel (1983) proposed an equilibrium criterion for analysing tailings beach slopes based on the height of the tailings layer, the shear strength and $\gamma$. If the shear strength is considered as $\tau_{y}$, the height of the tailings layer using the Blight and Bentel (1983) analysis becomes the maximum height of a tailings layer that can be maintained stagnant for a given basal beach slope (Li 2011). 
Equation 15 presents this maximum height $H_{p}$ (considering $\sin \theta \approx \theta$ when $\theta$ is small).

$$
H_{p}=\frac{\tau_{y}}{\gamma \theta_{\text {beach }}}
$$

Provided that this criteria is accepted, concavity could be explained by means of the presence of tailings with different $\tau_{y}$ along a beach profile (i.e. with different basal angles along the beach for staying in equilibrium, originating the observed concavity).

This $\tau_{y}$ variation can be produced due to tailings variability during the beach formation process (where high yield stress tailings remains near the discharge with higher beach slopes and low yield stress tailings flows far away from the discharge being placed with lower beach slope) and due to yield stress changes in the tailings flow driven by changes in solid concentration (generated by solid losses) during the fluid travel across the beach (McPhail et al. 2017).

A steady-state beach profile can be characterised by having equal increments of the vertical height at each point of the profile for a given period of time (i.e. the only way for preserving its particular geometry during the tailings beach growth).

Considering a steady-state concave beach profile with an arbitrary geometry, the following expression can be proposed as a characteristic condition of any steady beach profile in equilibrium.

$$
\frac{\tau_{y}(x)}{\gamma(x) \theta_{\text {beach }}(x)}=k_{s} \quad \forall x \in(0, L)
$$

where:

$$
\begin{aligned}
& k_{S} \quad=\text { constant value (discussed below). } \\
& x \quad=\text { horizontal variable of the beach profile. Distance from the spigot discharge point. } \\
& L \quad=\text { total length of the beach profile. }
\end{aligned}
$$

The constant $k_{s}$ represents the constant tailings increment of height at any point, that in particular can be the height of the tailings flow considering the condition $N=1$ presented in Section 3 given by Equation 17 .

$$
k_{s}=\sqrt{\frac{6 Q \eta}{\tau_{y} W}}
$$

Considering that $\theta_{\text {beach }}=d z / d x$ (the variation of the profile elevation $z$ with respect to the horizontal distance $x$ ), from Equation 16 it is possible to derive the following differential equation for the beach profile, representing that the slope at any point of the profile is related to the balance between the yield stress (the resistant component) and the forces associated to the tailings unit weight (the driving component).

$$
\frac{\tau_{y}(x)}{\gamma(x)}=k_{s} \frac{d z}{d x}(x)
$$

where:

$z \quad=\quad$ vertical elevation of the beach profile as a function of $x$.

Integrating Equation 18 allows for having the following expression for the estimation of a concave steady-state beach profile.

$$
z(x)=z_{x=0}-\frac{1}{k_{s}} \int_{0}^{x} \frac{\tau_{y}(x)}{\gamma(x)} d x
$$




\subsubsection{Screening level assessment of concavity}

The effect of concavity can be addressed through a simplistic mass balance for screening level purposes if yield stress is modified along the beach due to changes in the solids concentration of the tailings. Figure 3 presents the mass balance considered, in which the solids concentration of a discrete element of tailings traveling with certain horizontal velocity is reduced due to the presence of a vertical velocity of solid deposition at the base of the flow. Equations 20, 21 and 22 represent the components of this mass balance.

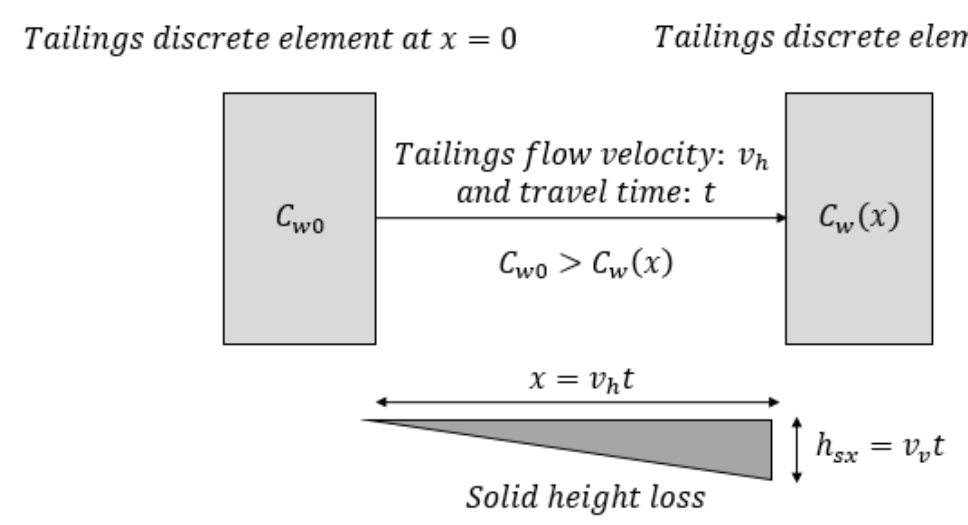

Figure 3 Schematic of simplified mass balance model for solid content variation in a tailings flow

$$
\begin{gathered}
C_{w 0}=\frac{h_{s o} S_{G}}{h_{s o} S_{G}+h_{w o}} \\
C_{w}(x)=\frac{h_{s o} s_{G}-h_{s x}}{h_{s o} S_{G}-h_{s x}+h_{w o}} \\
h_{s x}=\frac{v_{v}}{v_{h}} x=\xi x
\end{gathered}
$$

where:

$$
\begin{array}{ll}
C_{w 0} \text { and } C_{w}(x) & =\text { solids concentration at } x=0 \text { and solids concentration at } x . \\
S_{G} & =\text { tailings particles specific gravity. } \\
h_{s o}, h_{w o} \text { and } h_{s x} & =\text { initial solid and water height, and accumulated deposited solid height at } x . \\
v_{v} \text { and } v_{h} & =\text { vertical settling velocity of solids and horizontal flow velocity. } \\
\xi & =\text { velocity ratio (vertical settling velocity of solid to horizontal flow velocity). }
\end{array}
$$

Equation 23 (considering Equations 24 and 25) gives the final expression of the solids concentration along the beach, combining Equations 20, 21 and 22.

$$
\begin{gathered}
C_{w}(x)=\frac{F-\xi \frac{x}{H}}{F(1+C)-\xi \frac{x}{H}} \\
F=\frac{C_{w 0} S_{G}}{\left(C_{w 0}\left(1-S_{G}\right)+S_{G}\right)} \\
C=\frac{\left(1-C_{w 0}\right)}{C_{w 0}}
\end{gathered}
$$

Having the solid concentration variation, it is possible to associate $C_{w}$ with $\tau_{y}$ through the following expression, valid for given tailings sample.

$$
\tau_{y}=\left[A+B C_{w}\right]^{\alpha}
$$

where:
$A, B$ and $\alpha$
$=$ parameters representing the variation of the yield stress with respect to the solids content.


Then, using Equation 23 and 26, it is possible to have an expression for the variation of $\tau_{y}$ along the beach profile.

$$
\tau_{y}(x)=\left[A+B\left(\frac{F-\xi_{\frac{x}{H}}^{x}}{F(1+C)-\xi \frac{x}{H}}\right)\right]^{\alpha}
$$

In these terms, an expression for the variation of the tailings unit weight along the beach profile could be obtained in the same way, considering its direct relationship with the solids content and the specific gravity of the particles.

Figure 4 presents a schematic representation of yield stress variation along the beach due to tailings type variability (i.e. mineralogy and particle size distribution) and thickener performance variability during the beach formation period. This illustrates a scenario where, for example, if production of tailings with low yield stress are sustained in some period of time, these tailings would end depositing in the lower portion of the beach profile, altering the as-placed yield stress profile along the beach as it is shown in Figure 4.

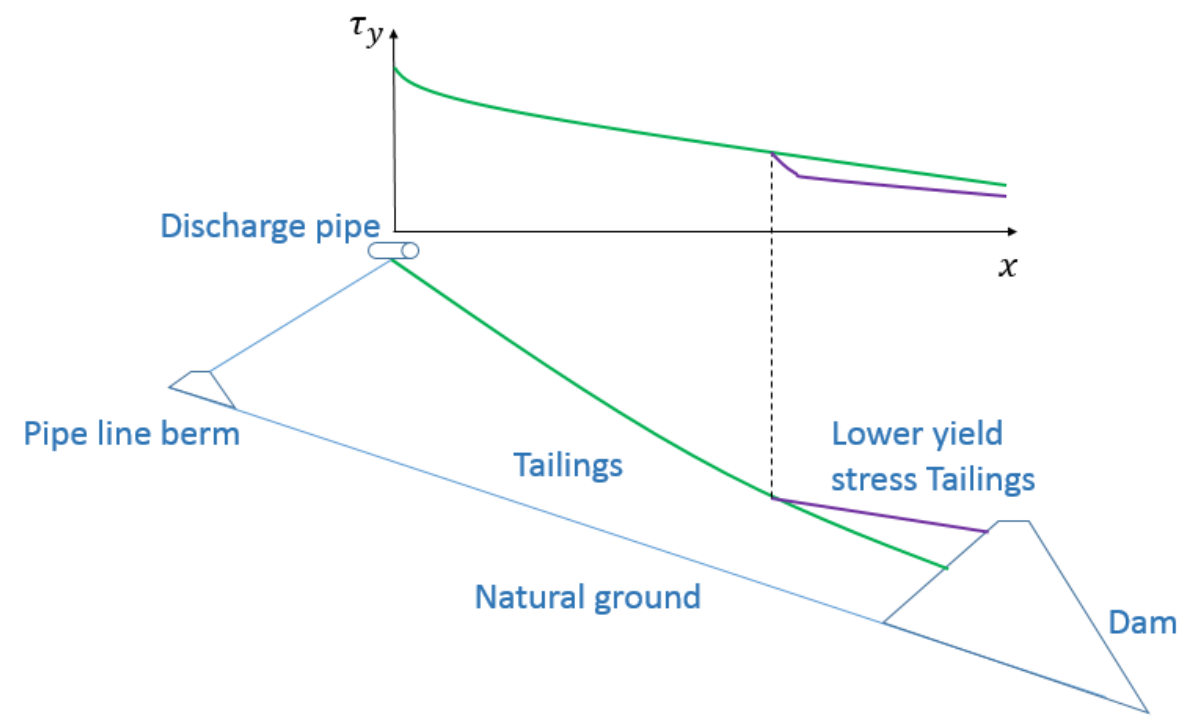

Figure 4 Schematic of a coupled representation of the yield stress variation along the beaches

The screening level assessment was completed by combining the yield stress variation along the beach due to the variation of solids concentration and tailings variability at the discharge point, through Equation 28 . This represents the overall behaviour of the green and purple curves sketched in Figure 4 . This requires proper judgement of the expected project condition.

$$
\tau_{y}(x)=\varphi e^{\mu x}
$$

where:

$$
\begin{aligned}
& \varphi \text { and } \mu= \text { constants to be defined. } \varphi \text { represents yield stress at } x=0 \text { and } \mu \text { controls the yields } \\
& \text { stress variation. }
\end{aligned}
$$

Equation 29 is obtained by solving the integration of Equation 19 considering the yield stress variation along the beach provided by Equation 28 and neglecting the variation of the tailings unit weight as follows.

$$
z(x)=z_{x=0}-\theta_{\text {beach }(x=0)} \frac{\left(e^{\mu x}-1\right)}{\mu}
$$

Equation 29 provides a simple tailings beach profile expression, based on the estimation of the initial tailings beach slope considering sheet flows $\theta_{\text {beach }(x=0)}$ (from Equation 14) and a single parameter $\mu$ with the potential of representing a variety of possible causes of yield stress variation along the beaches which govern the concavity of the beach profile. 


\section{$4 \quad$ Analysis of some cases histories}

The beach slope model and the beach profile model presented in this article are analysed with data available in the specialised literature for two sites. These cases are referred to as Case $A$, copper tailings operation presented by McPhail et al. (2017), and Case B, gold tailings operation presented by Simms et al. (2011) in which drying cycles of the beaches took place.

\subsection{Case A}

The required information for model verification was obtained from McPhail et al. (2017) and the parameters used in this work are shown in Table 1.

Table 1 Tailings flow data used for the model verification (from McPhail et al. 2017)

\begin{tabular}{llllll}
\hline $\begin{array}{l}\text { Tailings } \\
\text { production (tpd) }\end{array}$ & $\begin{array}{l}\text { Specific } \\
\text { gravity }\end{array}$ & $\begin{array}{l}\text { Solid content } \\
\mathbf{C w}(\%)\end{array}$ & $\begin{array}{l}\text { Yield stress } \\
(\mathbf{P a})\end{array}$ & $\begin{array}{l}\text { Plastic viscosity } \\
(\mathbf{P a} * \mathbf{s})\end{array}$ & $\begin{array}{l}\text { Number of } \\
\text { spigots }\end{array}$ \\
105,000 & 2.7 & 65 & 13 & 0.047 & 20 \\
\hline
\end{tabular}

The direct application of the dimensionless parameter $\theta_{\text {beach }}$ (Equation 14) gives a beach slope of $2.4 \%$. This represents an excellent agreement with field data, as shown in Figure 5 (first metres of the modelled profile). The total width $\mathrm{W}$ required for complete sheet flow development is estimated by the model (Equation 13) as $23 \mathrm{~m}$. This is the width associated with the flow that is flowing in a steady state with $2.4 \%$ of beach slope.

Then, knowing that the number of spigots used is 20 (operating simultaneously), a value of $1.2 \mathrm{~m}$ of width per each spigot flow is obtained from the model. Considering that fluid height $\mathrm{H}$ (Equation 5 ) is estimated as $0.05 \mathrm{~m}$, then the $\mathrm{W} / \mathrm{H}$ ratio is greater than 20 for each flow, indicating that sheet flow equations are reasonably valid for this case.

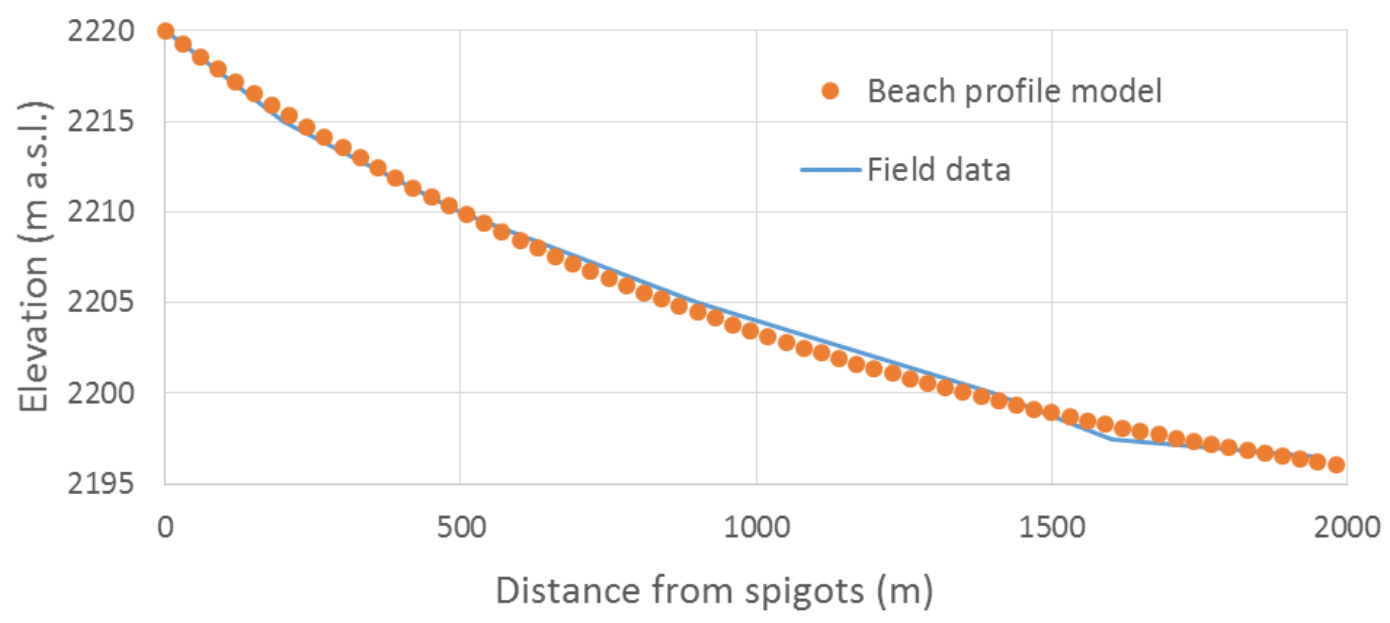

Figure 5 Measured beach profile at Case A (field data form McPhail et al. 2017) and model results

Results of the beach profile using Equation 29 are shown in Figure 5, considering the estimated $\theta_{\text {beach } x=0}$ of $2.4 \%$, the beach profile model and a value of $\mu$ equal to -0.0008 for calibrating the measured beach profile in the field.

The model exhibits good correlation with the measured beach profile. The variation of the yield stress at the beaches that allows the model to reproduce the beach profile observed is shown in Figure 6 . The well calibrated beach profile suggests that Equation 28 is a proper mathematical formulation for describing yield stress variation at beaches. 


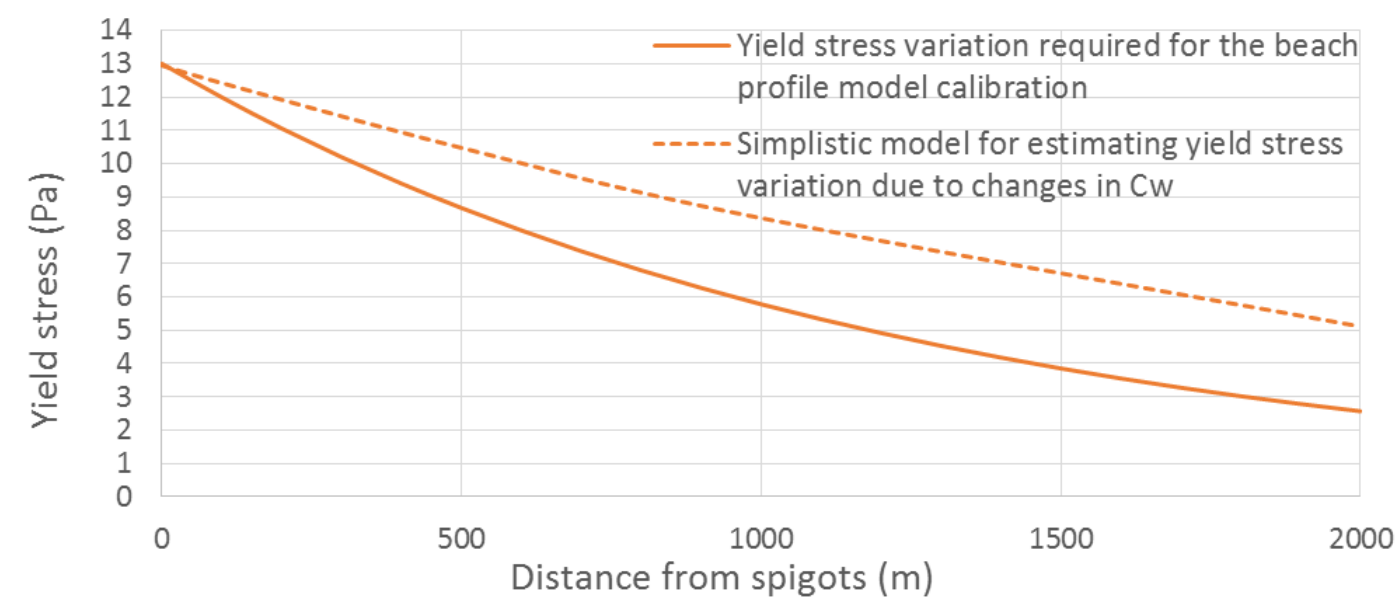

Figure 6 Yield stress variation along the beach required for model calibration and simplified model results for yield stress variation due to changes in the solids concentration

Concavity of beach profiles was also evaluated with Equation 27 by considering:

- The velocity of the flow, estimated as $1 \mathrm{~m} / \mathrm{s}$ (Equation 6).

- The relationship between Cw and yield stress, derived from the McPhail et al. (2017) data.

- Vertical settling velocity taken from similar copper tailings settling tests at $\mathrm{Cw} 65 \%$ (with an average hindered settling velocity of $3.6 \mathrm{E}-6 \mathrm{~m} / \mathrm{s}$ for descending the first $1 \mathrm{~cm}$ ).

The yield stress variation model results are shown in Figure 6, together with the yield stress profile that allows calibrating the field data. These results show that this simplistic model can provide a reasonable approximation of the degree of yield stress variation (considering that Equation 27 does not include other possible sources of yield stress variation, as was illustrated in Figure 4).

\subsection{Case B}

The required information for model verification was obtained from Simms et al. (2011) and the parameters used in this work are shown in Table 2.

Table 2 Tailings flow data used for the model verification (Simms et al. 2011)

\begin{tabular}{llllll}
\hline $\begin{array}{l}\text { Tailings } \\
\text { production (tpd) }\end{array}$ & $\begin{array}{l}\text { Specific } \\
\text { gravity }\end{array}$ & $\begin{array}{l}\text { Solid content } \\
\mathbf{C w}(\%)\end{array}$ & $\begin{array}{l}\text { Yield stress } \\
(\mathrm{Pa})\end{array}$ & $\begin{array}{l}\text { Plastic viscosity } \\
(\mathrm{Pa} * \mathbf{s})\end{array}$ & $\begin{array}{l}\text { Number of } \\
\text { spigots }\end{array}$ \\
2,507 & 3.0 & 72.8 & 50 & 0.1 & 1 \\
\hline
\end{tabular}

The direct application of the dimensionless parameter $\theta_{\text {beach }}$ (Equation 14) gives a beach slope of $8.4 \%$. This represents an excellent agreement with field data, as shown in Figure 7 (first metres of the modelled profile). The total width $\mathrm{W}$ required for a complete sheet flow development is estimated by the model (Equation 13) as $0.25 \mathrm{~m}$. This is the width associated with the flow that is moving in a steady state with $8.4 \%$ of beach slope. 


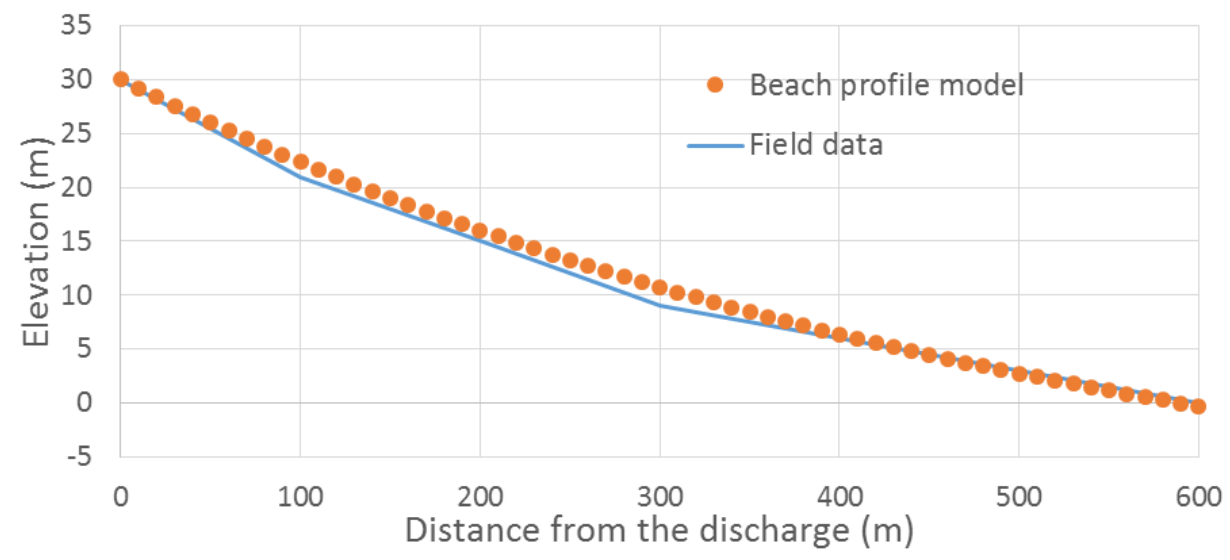

Figure 7 Measured beach profile at Case B (field data from Simms et al. 2011) and model results

Then, knowing that the number of spigots used is one (a discharge tower discharge), a value of $0.25 \mathrm{~m}$ of width from the tower flow is obtained from the model. Considering that fluid height $\mathrm{H}$ (Equation 5 ) is estimated as $0.05 \mathrm{~m}$, then the $\mathrm{W} / \mathrm{H}$ ratio is greater than five for the single flow, indicating that sheet flow equations are reasonably valid for this case.

Results of the beach profile using Equation 29 are shown in Figure 7, considering the estimated $\theta_{\text {beach } x=0}$ of $8.4 \%$, the beach profile model and a value of $\mu$ equal to -0.002 for calibrating the measured beach profile in the field.

The model exhibits good correlation with the measured beach profile. The variation of the yield stress at the beaches that allows the model to reproduce the beach profile observed is shown in Figure 8 . The well calibrated beach profile suggests that the yield stress should decay until $16 \mathrm{~Pa}$ at the end of the beach. Data for applying the simplistic model of yield stress variation is not available in Simms et al. (2011).

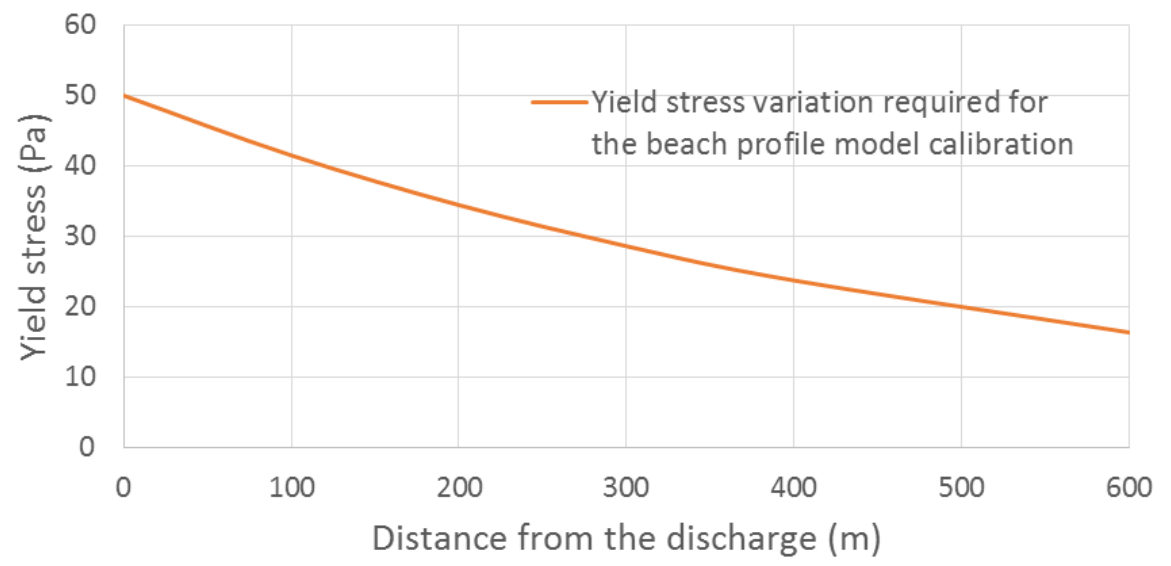

Figure 8 Yield stress variation along the beach required for model calibration

\section{$5 \quad$ Design and operational considerations}

Considerations envisioned for promoting sheet flows at the impoundment and preliminary stability requirement for the beach formation process are presented in this section.

\subsection{Site condition, design and operational drivers for promoting sheet flows}

As has been pointed out, the drying process is a key aspect for promoting tailings sheets flows. The primary factor for the drying process is climate that favours project sites with sufficient evaporation rates. Also, the topography of the project site is a relevant factor. Sites with large available deposition areas and regular natural ground topographies are more suitable for developing sheet flows from the earlier stages of the operation. 
Considering the sheet flow features provided in Section 3, a fundamental operational requirement can be derived considering the yield stress at the bottom of a sheet flow and a previously deposited tailings layer $\tau_{b}$. The yield stress at the bottom of the sheet flow of height $H$ (i.e. at the top of previously deposited tailings layer) and the yield stress at the bottom of the previously deposited tailings layer of height $H_{p}$ is given approximately by Equation 30, considering $\sin \theta \approx \theta$ for small values of $\theta$ and that $\gamma$ is the same for the sheet flow and the previously deposited tailings layer. This means that for having a layer by layer tailings beach formation by means of sheet flows, the previously deposited tailings layer requires at least having a yield stress of about $\frac{5}{2} \tau_{y}$.

This can be possible only if the previously deposited tailings layer was subject to a sufficient drying in order to reach at least about 2.5 times the yield stress of its fresh condition. Thus, in order to have sheet flows, during operation tailings should be discharged in the same location during a limited period of time to fill a certain area only with one layer of fresh tailings above dried beaches, and moving to another area with dried tailings surfaces for the next sheet flow discharge.

$$
\tau_{b}=\left\{\begin{array}{c}
\gamma H \theta_{\text {beach }}=\frac{3}{2} \tau_{y} \quad \text { at the base of the sheet flow } \\
\gamma\left(H+H_{p}\right) \theta_{\text {beach }}=\frac{5}{2} \tau_{y} \quad \text { at the base of the previously deposted layer }
\end{array}\right.
$$

The above statements suggest that operating by sectors further promotes formation of sheet flows.

Equation 31 can express the required drying times per sector. This equation takes into account the rate of rise and the effects of having more deposition sectors. In deposits with low tailings production rate with respect to the total impoundment area, drying times can be longer. Moreover, Equation 31 shows a powerful tool for increasing drying times related to the number of sectors used even in the same total impoundment area. For example, through this equation it may be observed that an increment of $60 \%$ of drying times at the beaches may be obtained if comparing sequencing of two sectors versus five sectors of active deposition.

$$
\text { Drying time }=\frac{(m-1)}{m}\left(\frac{A h_{f} S_{G}}{P(1+e)}\right)
$$

where:

$$
\begin{array}{ll}
A \text { and } m & =\text { total impoundment area and number of sectors within the impoundment. } \\
e & =\text { void ratio of the tailings fresh layer at the end of the sector operation. } \\
h_{f} & =\text { height of the tailings deposited fresh layer at the end of the sector operation. } \\
P & =\text { tailings production rate. }
\end{array}
$$

\subsection{Stability requirements for the beach formation process}

Shear strength requirements to meet stability criteria for beach slopes may be obtained with Equation 33, which is the same expression obtained by Jefferies and Been (2015) for post-liquefaction stability of an infinite gentle slope of consolidated soil/tailings with a phreatic level at the tailings surface. This equation may be derived by analogy from Equation 32, considering that the yield stress is the equivalent of the residual shear strength of a soil (i.e. considering even a post-liquefaction case). In this regard, it may be considered that as the tailings thickness increases throughout deposition (Equation 32), so should the tailings yield stress in depth to maintain a stable configuration. 


$$
\begin{gathered}
H_{p}=\frac{\tau_{y}}{\gamma \theta_{\text {beach }}} \Rightarrow \overline{H_{p}}=\frac{S_{r}}{\gamma \theta_{\text {beach }}} \\
\frac{S_{r}}{\sigma_{v o}^{\prime}}=\frac{\gamma}{\gamma^{\prime}} \theta_{\text {beach }}
\end{gathered}
$$

where:

$$
\begin{aligned}
\overline{H_{p}}= & \text { total height of the profile from the natural ground (sum of multiple layers, } \\
& \text { having } \left.\bar{H}=\frac{\sigma_{v o}^{\prime}}{\gamma^{\prime}}\right) . \\
= & \text { residual shear strength. } \\
= & \text { buoyant tailings unit weight }\left(\gamma^{\prime}=\frac{\gamma}{\gamma-\gamma_{w}} \text { where } \gamma_{w}\right. \text { is water unit weight). } \\
S_{r}^{\prime} & \text { vertical effective stress and residual shear strength ratio. }
\end{aligned}
$$

Equation 33 provides the minimum residual shear strength ratio for having $\theta_{\text {beach }}$ in a stable condition (infinite slope), even in a post-liquefaction condition (i.e. Factor of Safety of one). A relevant design and operation feature arises as the residual shear strength depends on the current state of the soil (Jefferies and Been 2015). If the drying of tailings beaches is increased, the current state of the tailings at the beaches should become a denser state and the residual shear strength ratio should be greater, allowing steeper stable beaches.

In addition, examining Equation 33, the maximum beach slope is dependent on the ratio between total unit weight and buoyant unit weight. Then, when unsaturated conditions are promoted by means of drying of the beaches (i.e. buoyancy is not acting, but sufficient water content keeps a liquefaction potential), higher beach slope angles may be achieved without compromising post-liquefaction stability criteria. For unsaturated cases, once the ratio between total and buoyant density is equal to one (neglecting in a conservative way suction pressures) the maximum achievable slope value equals the shear strength ratio.

The above is illustrated in Figure 9, which shows a conceptual preliminary assessment considering Equation 33 and the residual strength ratio dependence with the in situ state, using the data from Jefferies and Been (2015), related with intermediate compressibility soils.

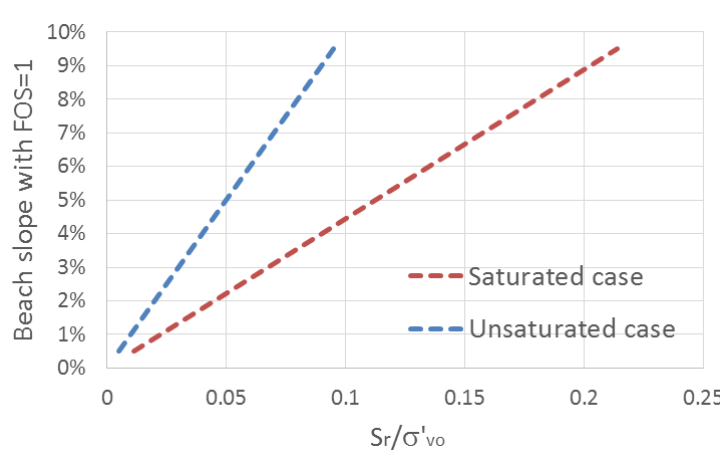

(a)

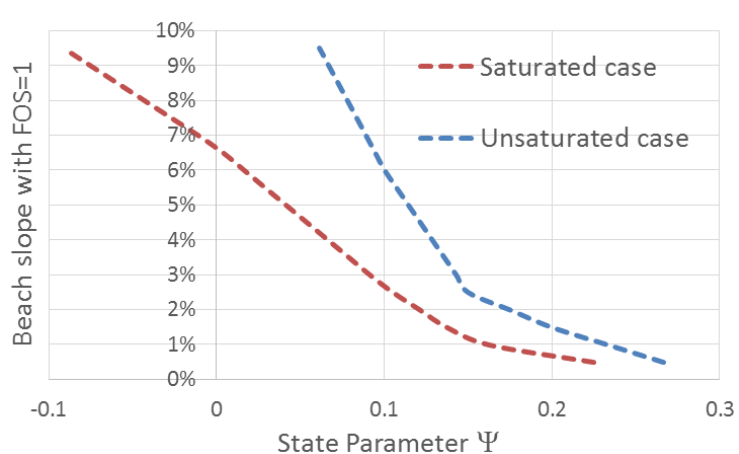

(b)

Figure 9 Maximum stable beach slope considering an infinite slope limit equilibrium; (a) In terms of the residual shear strength ratio; and, (b) In terms of the state parameter. Considering referential tailings properties

As shown, a $3 \%$ tailings beach slope would require a residual strength ratio at least of 0.07 for a saturated and consolidated condition, and of 0.03 for an unsaturated condition. Likewise, such beach slope would require a state parameter lower than 0.09 for a saturated and consolidated condition, and lower than 0.14 for the unsaturated case. The greater the void ratio reduction of tailings due to drying, the lower the state parameter (where the state parameter is a well-known soil mechanics value representing the in situ state (Been \& Jefferies 1985). 


\section{Conclusion}

This work presents a beach slope model considering a dimensionless parameter that captures the critical condition for which a non-Newtonian fluid (tailings) in sheet flow regime allows the formation of inclined tailings beaches. The model estimates beach slope angles based on the discharge rate, the fluid Bingham model properties and the fluid density. This work also allows for the formulation of an additional model to estimate beach profile concavity which correlates well with data measured in the field.

The primary conclusion is that a thin-layer deposition scheme with multiple spigots allowing drying cycles (when the site condition are favourable - mainly the climate and the topography) is a key driver to achieve more inclined and stable tailings beach slopes, including post-liquefaction condition.

As a design and operational recommendation, operating by sectors can provide further flexibility to manage thickness of fresh tailings during deposition, discharge times and drying times for the benefit of ensuring stable and steeper beach slopes.

\section{Acknowledgement}

The author thanks Eduardo Salfate from Golder Associates for his valuable review of this paper.

\section{References}

Been, K \& Jefferies, MG 1985, 'A state parameter for sands', Géotechnique, vol. 35, no. 2, pp. 99-112.

Blight, GE \& Bentel, GM 1983, 'The behaviour of mine tailings during hydraulic deposition', Journal of the South African Institute of Mining and Metallurgy, April 1983, pp. 73-86.

Fitton, TG 2007, Tailings Beach Slope Prediction, PhD thesis, RMIT University, Melbourne, (since published as a book by VDM Verlag, Saarbrucken in 2010).

Fourie, AB \& Gawu, SKY 2010, 'The validity of laboratory flume data for predicting beach slopes of thickened tailings deposits', in RJ Jewell and AB Fourie (eds), Proceedings of the 13th International Seminar on Paste and Thickened Tailings, Australian Centre for Geomechanics, Perth, pp. 241-253.

Ihle, CF \& Tamburrino, A 2009, 'Proposed scaling laws for laminar flow of a Bingham plastic down an inclined plane', in RJ Jewell, AB Fourie, S Barrera and J Wiertz (eds), Proceedings of the 12th International Seminar on Paste and Thickened Tailings, Australian Centre for Geomechanics, Perth, pp. 225-232.

Jefferies, MG \& Been, K 2015, Soil Liquefaction: A Critical State Approach, 2nd edn, Taylor and Francis, Abingdon, 690 p.

Jewell, RJ 2010, 'The evolution of paste and thickened tailings', Newsletter of the Australian Centre for Geomechanics, vol. 35, pp. 1-3.

Li, AL 2011, 'Prediction of tailings beach slopes and tailings flow profiles', in RJ Jewell and AB Fourie (eds) Proceedings of the 14th International Seminar on Paste and Thickened Tailings, Australian Centre for Geomechanics, Perth, pp. 307-322.

McPhail, GI 1995, Prediction of the Beaching Characteristics of Hydraulically Placed Tailings, PhD dissertation, University of the Witwatersrand, Johannesburg.

McPhail, GI 2008, 'Prediction of the beach profile of high-density thickened tailings from rheological and small-scale trial deposition data', in AB Fourie, RJ Jewell, P Slater, A Paterson (eds), Proceedings of the 11th International Seminar on Paste and Thickened Tailings, Australian Centre for Geomechanics, Perth, pp. 179-188.

McPhail, GI 2015, 'Simulation of the meandering flow path of a beaching slurry using a random walk technique', in RJ Jewell and AB Fourie (eds), Proceedings of the 18th International Seminar on Paste and Thickened Tailings, Australian Centre for Geomechanics, Perth, pp. 467-475.

McPhail, GI, Bello, F \& Engels, J 2017, 'Beach profile modeling at Centinela Mine, Chile', Proceedings of the 4th International Seminar on Tailings Management, Gecamin, Santiago.

Naik, B 1883, 'Mechanics of mudflow and treated as the flow of a Bingham fluid', PhD thesis, Washington State University, Pullman.

Pirouz, B \& Williams, MPA 2007, 'Prediction of non-segregating thickened tailings beach slopes - a new method', in AB Fourie and RJ Jewell (eds), Proceedings of the Tenth International Seminar on Paste and Thickened Tailings, Australian Centre for Geomechanics, Perth, pp. 315-327.

Simms, P, Williams, MPA, Fitton, TG \& McPhail, GI 2011, 'Beaching angles and evolution of stack geometry for thickened tailings - a review', in RJ Jewell \& AB Fourie (eds), Proceedings of the 14th International Seminar on Paste and Thickened Tailings, Australian Centre for Geomechanics, Perth, pp. 323-338. 
